\title{
Traction-assisted colonic endoscopic submucosal dissection using clip and line: a feasibility study
}

Authors

Institution
Yasushi Yamasaki, Yoji Takeuchi, Noriya Uedo, Minoru Kato, Kenta Hamada, Kenji Aoi, Yusuke Tonai, Noriko Matsuura, Takashi Kanesaka, Takeshi Yamashina, Tomofumi Akasaka, Noboru Hanaoka, Koji Higashino, Ryu Ishihara, Hiroyasu lishi

Department of Gastrointestinal Oncology, Osaka Medical Center for Cancer and Cardiovascular Diseases, Osaka, Japan
Bibliography

DOI http://dx.doi.org/

10.1055/s-0041-107779

Published online: 30.11 .2015

Endoscopy International Open

2016; 04: E51-E55

(c) Georg Thieme Verlag KG

Stuttgart $\cdot$ New York

E-ISSN 2196-9736

\section{Corresponding author}

Yoji Takeuchi, MD

Department of Gastrointestinal Oncology

Osaka Medical Center for

Cancer and Cardiovascular

Diseases

1-3-3, Nakamichi,

Higashinari-ku

Osaka 537-8511

Japan

Fax: +81-6-6981-4067

takeuti-yo@mc.pref.osaka.jp
Background and study aims: Colonic endoscopic submucosal dissection (ESD) is a challenging procedure because it is often difficult to maintain good visualization of the submucosal layer. To facilitate colonic ESD, we designed a novel traction method, namely traction-assisted colonic ESD using clip and line (TAC), and investigated its feasibility.

Patients and methods: We retrospectively analyzed 23 patients with large colonic superficial lesions who had undergone TAC. The main outcome was the procedural success rate of TAC, which we defined as successful, sustained application of clip

\section{Introduction}

\section{$\nabla$}

Colorectal endoscopic submucosal dissection (ESD) is a promising, minimally invasive procedure that enables high en bloc resection rates regardless of lesion size [1]. However, colorectal ESD, particularly colonic ESD, is a more challenging procedure than conventional endoscopic mucosal resection (EMR) because of its technical difficulties, longer procedure time, and higher risk of adverse events such as perforation $[1,2]$. Therefore, colonic ESD is not a standard therapy, especially not in Western countries [3].

All endoscopic procedures should be performed under direct visualization but visualization of the operating site is recommended, in particular, when performing ESD to enable precision sufficient to avoid perforation and bleeding. However, a major issue often encountered with colorectal ESD is difficulty in maintaining an adequate view during submucosal dissection because the mucosa cannot be lifted as in open surgery. Recently, a traction method using an endoclip and line called "clip with line" [4] was developed for maintaining good visualization of the submucosal layer during esophageal and gastric ESD [4-6]. This method made ESD easier and reduced the procedure time for submucosal dissection [6], but it is not applic- and line to the lesion until the end of the procedure.

Results: The procedural success rate of TAC was $87 \%(20 / 23)$. In all three unsuccessful cases, the lesions were in the proximal colon and the procedure times over 100 minutes. The overall mean procedure time was $61 \mathrm{~min}$ (95\% confidence interval, 18-172 min). We achieved en bloc resections of all lesions. There were no perforations or fatal adverse events.

Conclusions: TAC is feasible and safe for colonic ESD and may improve the ease of performing this procedure.

able to colonic ESD because the colonoscope had to be withdrawn to mount the endoclip and line [4]. To facilitate ESD and make it more widely available, particularly for colonic application, a simple and safe traction method is required.

We therefore designed a novel traction method traction-assisted colonic ESD using clip and line (TAC) - [7] that does not require withdrawal and reinsertion of the colonoscope. We herein present a feasibility study of our method of colonic ESD.

\section{Patients and methods \\ $\nabla$ \\ Patients}

We retrospectively enrolled 23 patients with large colonic superficial lesions who had undergone ESD at the Osaka Medical Center for Cancer and Cardiovascular Diseases between October 2014 and March 2015. Colonic lesions larger than $20 \mathrm{~mm}$ that were difficult to remove en bloc with conventional EMR were included. Lesions predicted to be noninvasive tumors and cancers with minute $(<1000 \mu \mathrm{m})$ submucosal invasion that were thought to carry no risk of lymphovascular metastasis were removed by ESD using the TAC method. Lesions larger than $50 \mathrm{~mm}$, showing a non-lifting sign or residual lesions after EMR 


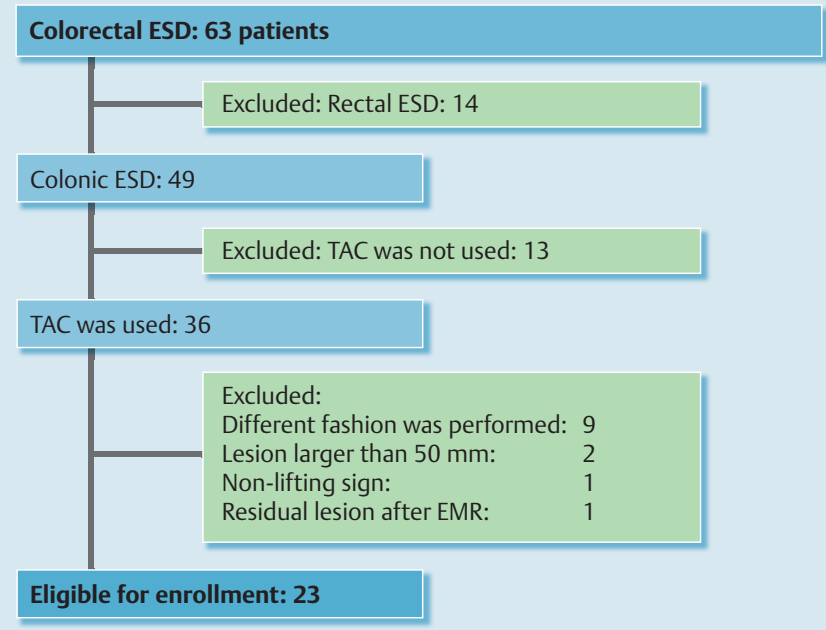

Fig. 1 Flow diagram for enrollment in the study (procedures performed from October 2014 to March 2015).

were excluded. Lesions using variations of TAC in which different types of clip or line were used were also excluded ( $\bullet$ Fig.1). Outcome measures were procedural success rate of $\mathrm{TAC}$, en bloc resection rate, complete en bloc resection (R0 resection) rate, procedure time, and adverse events. Procedural success of TAC was defined as successful sustained application of clip and line to the lesion until the end of the procedure. R0 resection was defined as en bloc resection with no tumor identified at the lateral or vertical margins. Procedure time was measured from the start of the submucosal injection until removal of the lesion. The procedure speed and the area of submucosa dissected per unit time $\left(\mathrm{mm}^{2} / \mathrm{min}\right)$ were calculated by dividing the dissection time into the size of the resected specimen. Specimen sized was calculated using the formula $\pi$ - the major axis - the minor axis/4. Histopathologic diagnoses were classified according to the Japanese classification[8]. This study was approved by the institutional review board and written informed consent for ESD was obtained from all patients.

\section{ESD procedures using the novel "TAC" method}

ESD was conducted using a colonoscope (PCF-Q260AZI or CFQ260DI; Olympus, Tokyo, Japan) with a distal attachment cap (D-201-13404; Olympus). TAC was performed in a uniform, standardized fashion as previously described [7]. Before the colonoscope was inserted, a polyester line measuring $0.2 \mathrm{~mm}$ in diameter and $3 \mathrm{~m}$ in length was inserted into its accessory channel by grasping the end of the line with hemostatic forceps (Coaglasper; FD-410LR, Olympus) and pulling it up through the working channel, and then tying the ends of the line together outside the colonoscope ( $\bullet$ Video 1$)$. After the line had been set up, the colonoscope was inserted $(\bullet$ Fig. 2, $\bullet$ Fig. 3 ) and the actual procedure started. All ESD procedures were performed using a Flush knife (1.5-mm, DK2618JN15, Fujifilm Medical, Tokyo, Japan) and 0.9\% saline solution was used as water-jet fluid. An electrosurgical generator (VIO 300D; ERBE, Tübingen, Germany) was used for all ESD procedures.

First, $0.4 \%$ hyaluronate sodium solution (MucoUp; Johnson \& Johnson K.K., Tokyo, Japan) was injected into the submucosa, after which the mucosa was incised on the anal side of the lesion. When the line interfered with endoscopic view, we changed the position of a patient's body, resulting in good visualization of the

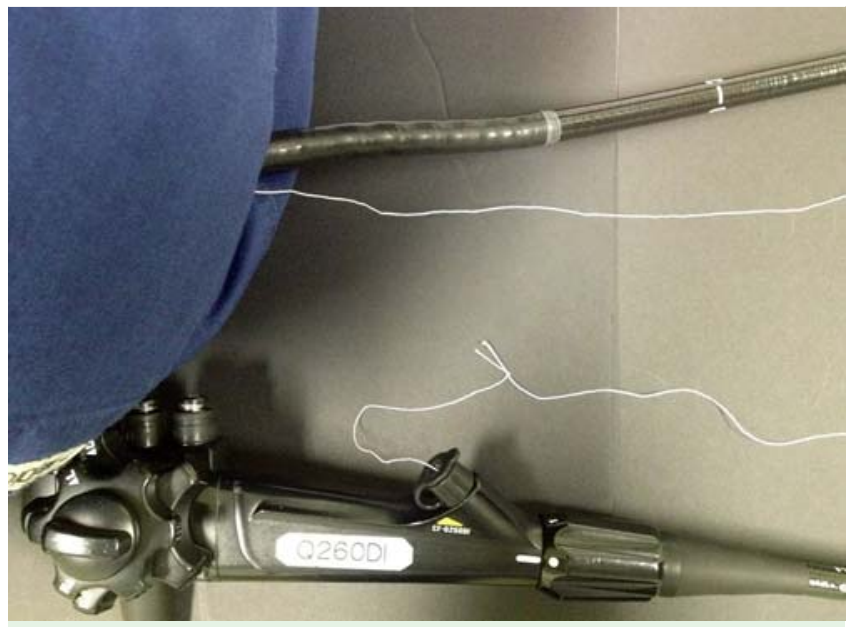

Fig. 2 The silk line is tied outside the colonoscope and the colonoscope inserted.

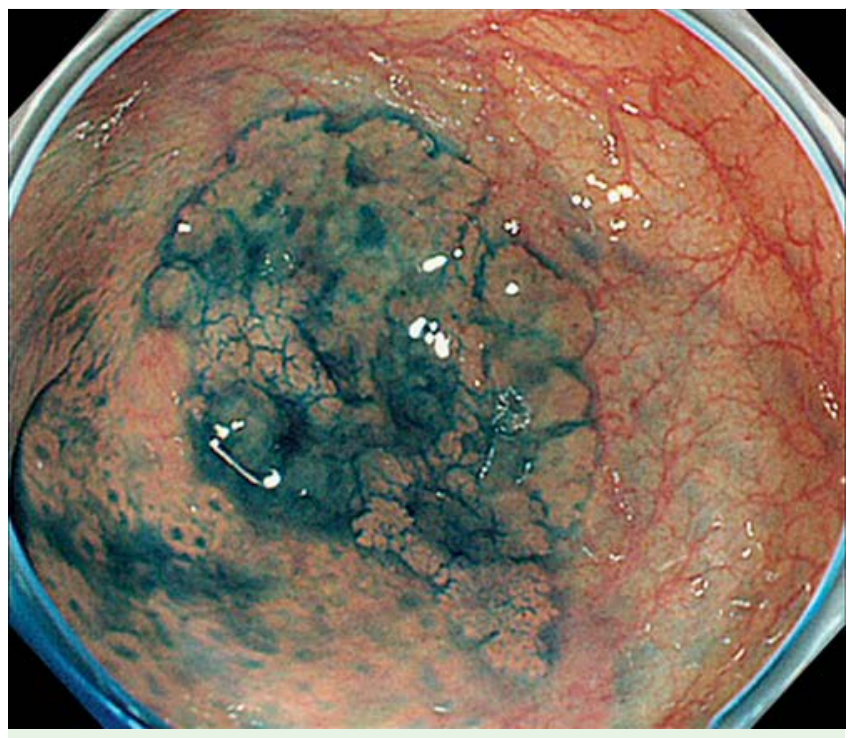

Fig. 3 Colonoscopy image showing a slightly elevated 30-mm lesion in the cecum.

\section{Video 1}

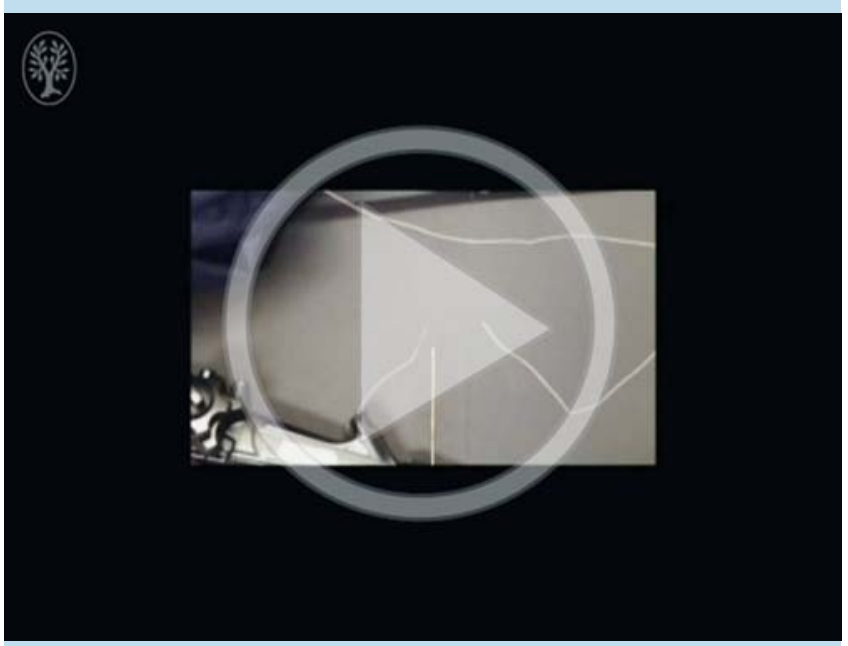

Colonic ESD using the novel traction method TAC Online content including video sequences viewable at: http://dx.doi.org/10.1055/s-0041-107779 


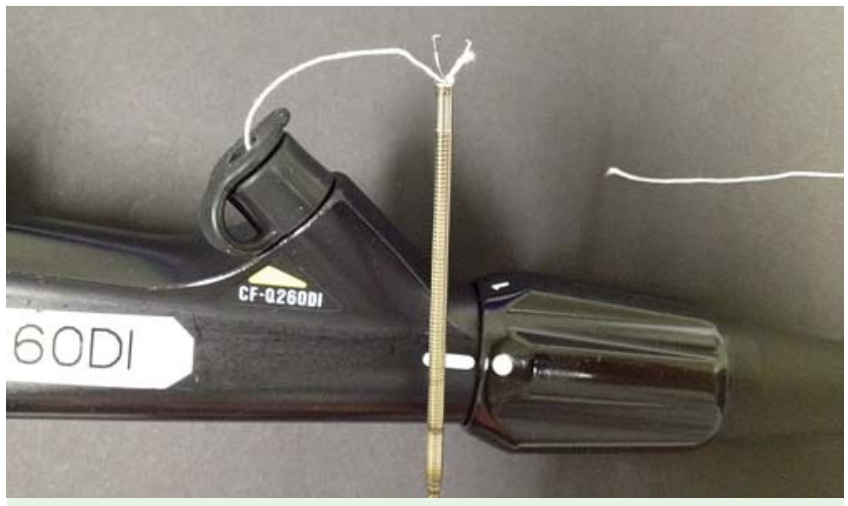

Fig. 4 The accessory channel side of the line is tied to the teeth of an endoclip that has not been fully opened.

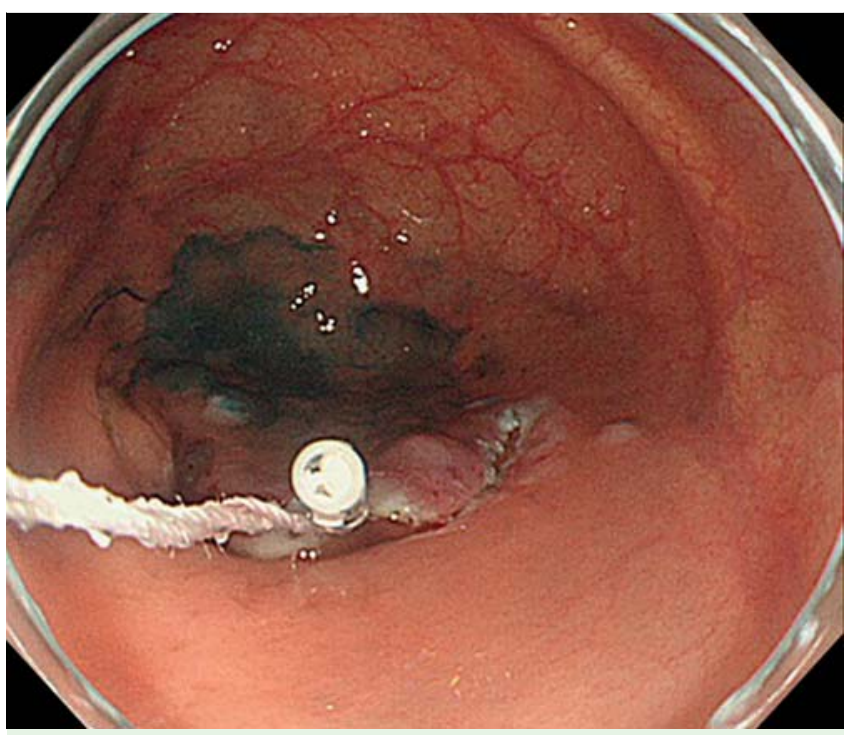

Fig. 5 The anal side of a lesion is grasped with the endoclip and line.

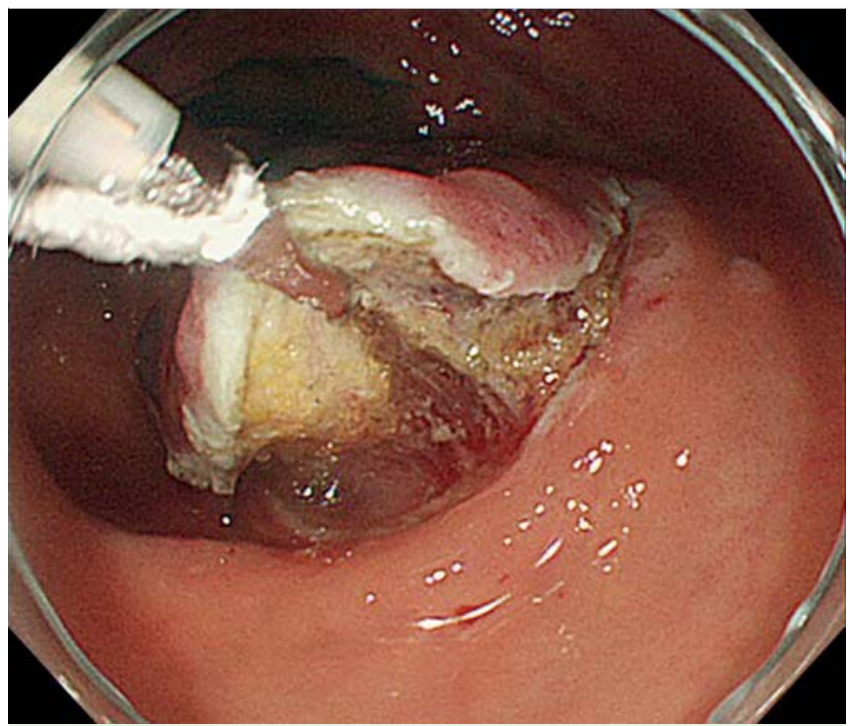

Fig. 6 The submucosal layer is lifted, achieving good visibility and making it easy to dissect the submucosal layer by keeping the submucosal layer an appropriate distance from the colonoscope. cutting line of the mucosa. Next, the line was cut externally at the hand control end of the colonoscope and the accessory channel end of the line tied to the teeth of an endoclip (HX-610-090; Olympus) attached to an applicator ( $\bullet$ Fig.4, $\bullet$ Video 1 ). At this stage, it was important not to fully open the endoclip. The clip and line were then retracted into the applicator and the applicator inserted into the accessory channel. The endoclip was fully opened in the colon and used to grasp the anal side of the specimen ( $\bullet$ Fig. 5, $\triangle$ Video 1 ), after which the line was pulled gently by hand ( $\bullet$ Fig. $6, \nabla$ Video 1 ) to provide good visibility of the submucosal layer.

Then, a distal attachment cap placed at the tip of scope was used to add traction and create angulation, which resulted in good visibility of the submucosal layer of dissection. Once the submucosal layer of dissection was visualized, we released the hand from the line. After the circumferential mucosal incision was completed, the submucosal layer was dissected easily under direct visualization. If more traction was needed, we pulled the line by hand again.

\section{Results}

Patient and lesion characteristics are shown in Table 1. The study subjects were 12 men and 11 women with a median age of 72 years (range 49 - 88 years). Eighteen (78\%) lesions were located in the proximal colon, and $48 \%$ of lesions were a granular type of laterally spreading tumor The median lesion size was 27 $\mathrm{mm}$ (range 20-44 $\mathrm{mm}$ ).

Outcomes of ESD using the TAC method are shown in Table 2. A clip and line was attached to the lesion until the procedure ended, thus maintaining good visibility of the submucosal layer in 20/23 subjects and resulting in a procedural success rate for TAC of $87 \%$. In three cases, during submucosal dissection, the endoclip detached from lesions, all of which were in the proximal colon.The procedure times for these lesions were over $100 \mathrm{~min}$ utes whereas the overall mean procedure time was $61 \mathrm{~min}(95 \%$ confidence interval [CI], 18-172 min.). The overall mean procedure speed was $16.7 \mathrm{~mm}^{2} / \mathrm{min}$ (95\% CI, 3.4-47.4 $\mathrm{mm}^{2} / \mathrm{min}$.). En bloc resections of all lesions were achieved and $\mathrm{R} 0$ resections confirmed in 22/23 lesions (96\%). The lateral margin of the remaining lesion was unclear on histologic examination. Pathologic examination revealed deep submucosal invasion or lymphatic invasion in four lesions; additional surgical resection with lymph node dissection was recommended for these patients. Delayed bleeding occurred in one lesion and was treated successfully with endoscopic hemostasis. There were no perforations or fatal adverse events.

\section{Discussion}

The novel traction method TAC was successfully applied in most cases in our trial. This simple technique does not require withdrawal and reinsertion of the colonoscope and takes only a few minutes to attain good visualization of the submucosal layer during procedure. We found that this method is feasible for colonic ESD.

Several traction techniques, such as sinker-assisted ESD [9], S-O clip [10], cross-counter technique [11], and clip flap [12], have been developed for facilitating colorectal ESD. Although these techniques can provide useful traction during colorectal ESD, 
Table 1 Patient characteristics.

\begin{tabular}{|c|c|c|}
\hline & $N=23$ & $(\%)$ \\
\hline Age, yr & $72(49-88)$ & \\
\hline Male/female, $n$ & $12 / 11$ & \\
\hline \multicolumn{3}{|l|}{ Lesion location, n } \\
\hline Cecum & 7 & (30) \\
\hline Ascending colon & 6 & (26) \\
\hline Transverse colon & 5 & $(22)$ \\
\hline Descending colon & 1 & (4) \\
\hline Sigmoid colon & 4 & $(17)$ \\
\hline \multicolumn{3}{|l|}{ Location group, $\mathrm{n}$} \\
\hline Proximal colon (transverse colon or above) & 18 & (78) \\
\hline Distal colon & 5 & (22) \\
\hline \multicolumn{3}{|l|}{ Paris classification, $\mathrm{n}$} \\
\hline 0 -Is & 6 & (26) \\
\hline $0-I s+11 a$ & 8 & (35) \\
\hline 0 -IIa & 6 & (26) \\
\hline 0 -IIC & 3 & (13) \\
\hline \multicolumn{3}{|l|}{ Morphology, n } \\
\hline Granular & 11 & $(48)$ \\
\hline Non-granular & 7 & (30) \\
\hline Unclassified & 5 & (22) \\
\hline Lesion size, mm & $27(20-44)$ & \\
\hline
\end{tabular}

NOTE: Values are expressed as median (range) unless otherwise noted.

they are not used extensively because of their limitations. Sinkerassisted ESD, S-O clip, and cross-counter technique require special devices or equipment to obtain traction. Clip flap is simple and helpful; however, being an indirect traction method, it does not always provide sufficient traction or ability to lift the lesion. In addition, clip flap does not suppress movement of a lesion caused by respiration or arterial pulsation. To address these difficulties, Oyama et al developed the "clip with line" method for esophageal and gastric ESD and reported its safety and usefulness [4]. This method has two advantages: first, adequate traction enables good visualization of the submucosal layer during submucosal dissection; and second, a clip and line fixes the specimens, thus preventing movement of the gastrointestinal wall caused by respiration or arterial pulsation. However, it is time consuming and painful because it withdrawal and reinsertion of the endoscope is required when this method is applied to colonic ESD. Therefore, we designed a novel "clip with line" fastening method for colonic ESD, which does not necessitate withdrawal and reinsertion of the colonoscope.

In a previous study, experienced endoscopists achieved a mean procedure time for colorectal ESD using Flush knife of 61 minutes (95\% CI 49-72) [13]. Although in the current study half the colonic ESDs were performed by endoscopy fellows under direct supervision of experienced endoscopists, all lesions were resected en bloc and the mean procedure time was comparable with that in our previous study. The mean procedure time and procedure speed for the 20 cases in which TAC remained attached to the lesion until the end of the procedure was $53 \mathrm{~min}(95 \% \mathrm{CI} 18-72)$ and $17.9 \mathrm{~mm}^{2} / \mathrm{min}\left(95 \% \mathrm{CI}, 3.4-47.4 \mathrm{~mm}^{2} / \mathrm{min}\right.$.), respectively (data not shown). Of these 20 cases, only one took over $100 \mathrm{~min}$ utes. These results suggest that this novel traction method reduces the procedure time for colonic ESD. In this study, the endoclip detached from three lesions, all of which were in the proximal colon. Two of those procedures were performed by experienced endoscopists and one was performed by endoscopic fellow. The procedure times for these lesions were over 100 minutes. It seems that prolonged procedure times in the proximal colon
Table 2 Outcomes of treatment.

\begin{tabular}{|c|c|c|}
\hline & $N=23$ & (\%) \\
\hline Successful rate of TAC & 20 & (87) \\
\hline Resected specimen size, mm & $35(23-60)$ & \\
\hline $\begin{array}{l}\text { Procedure time, min, mean } \\
\text { (95\% confidence interval) }\end{array}$ & $61(18-172)$ & \\
\hline $\begin{array}{l}\text { Procedure speed, } \mathrm{mm}^{2} / \mathrm{min} \text {, mean } \\
\text { ( } 95 \% \text { confidence interval) }\end{array}$ & $16.7(3.4-47.4)$ & \\
\hline \multicolumn{3}{|l|}{ Histology, $\mathrm{n}$} \\
\hline Tubular adenoma & 3 & \\
\hline Tubulovillous adenoma & 4 & \\
\hline Sessile serrated adenoma/polyp & 2 & \\
\hline $\begin{array}{l}\text { Intramucosal or minute submucosal } \\
\text { invasive cancer }\end{array}$ & 11 & \\
\hline Deeply submucosal invasive cancer & 3 & \\
\hline En bloc resection, $\mathrm{n}$ & 23 & $(100)$ \\
\hline R0 resection, $\mathrm{n}$ & 22 & (96) \\
\hline \multicolumn{3}{|l|}{ Adverse events, $n$} \\
\hline Delayed bleeding & 1 & (4) \\
\hline Intraoperative perforation & 0 & (0) \\
\hline Delayed perforation & 0 & \\
\hline
\end{tabular}

NOTE: Values are expressed as median (range) unless otherwise noted.

TAC, traction-assisted colonic ESD using clip and line

Minute submucosal invasive cancer: $\mathrm{SM}<1000 \mu \mathrm{m}$

Deeply submucosal invasive cancer: $S M \geq 1000 \mu \mathrm{m}$

can create so much friction on the clip and line that they detach from the specimen. With proximal colon lesions, we therefore recommend pulling gently on the line.

Even though we have shown that this novel traction method is feasible, this study does have several limitations. First, it was a small, retrospective, single-center study. Further prospective studies are warranted to assess the efficacy of this method for colorectal ESD. Second, the procedures were performed by four experienced endoscopists and four supervised endoscopy fellows, making it difficult to accurately assess what the en bloc resection rate would be in less experienced hands. Therefore, other outcome measures must be identified for checking the validity of our method.

In this feasibility study, we demonstrated that the TAC method is feasible and safe for colonic ESD. Further prospective randomized studies are needed to fully evaluate the usefulness of this method.

\section{Competing interests: None}

\section{References}

1 Takeuchi $Y$, Iishi $H$, Tanaka $S$ et al. Factors associated with technical difficulties and adverse events of colorectal endoscopic submucosal dissection: retrospective exploratory factor analysis of a multicenter prospective cohort. Int J Colorectal Dis 2014; 29: 1275-1284

2 Lee EJ, Lee JB, Lee SH et al. Endoscopic submucosal dissection for colorectal tumors - 1000 colorectal ESD cases: one specialized institute's experiences. Surg Endosc 2013; 27: 31 - 39

3 Moss A, Williams SJ, Hourigan LF et al. Long-term adenoma recurrence following wide-field endoscopic mucosal resection (WF-EMR) for advanced colonic mucosal neoplasia is infrequent: results and risk factors in 1000 cases from the Australian Colonic EMR (ACE) study. Gut 2015; 64: $57-65$

4 Oyama T. Counter traction makes endoscopic submucosal dissection easier. Clin Endosc 2012; 45: 375 - 378

5 Ota M, Nakamura T, Hayashi K et al. Usefulness of clip traction in the early phase of esophageal endoscopic submucosal dissection. Dig Endosc 2012; 24: $315-318$ 
6 Koike $Y$, Hirasawa D, Fujita $N$ et al. Usefulness of the thread-traction method in esophageal endoscopic submucosal dissection: Randomized controlled trial. Dig Endosc 2015; 27: 303 - 309

7 Yamasaki Y, Takeuchi Y, Hanaoka $\mathrm{N}$ et al. A novel traction method using an endoclip attached to a nylon string during colonic endoscopic submucosal dissection. Endoscopy 2015; 47: E238 - 239

8 Japanese Society for Cancer of the Colon and Rectum. editor. Japanese Classification of Colorectal Carcinoma 2nd ed. Tokyo: Kanehara \& Co. Ltd; 2009

9 Saito Y, Emura F, Matsuda $T$ et al. A new sinker-assisted endoscopic submucosal dissection for colorectal tumors. Gastrointest Endosc 2005; 62: 297-301
10 Sakamoto N, Osada T, Shibuya T et al. Endoscopic submucosal dissection of large colorectal tumors by using a novel spring-action S-O clip for traction (with video). Gastrointest Endosc 2009; 69: 1370-1374

11 Okamoto K, Muguruma N, Kitamura S et al. Endoscopic submucosal dissection for large colorectal tumors using a cross-counter technique and a novel large-diameter balloon overtube. Dig Endosc 2012; 24: 96-99

12 Yamamoto K, Hayashi S, Saiki $H$ et al. Endoscopic submucosal dissection for large superficial colorectal tumors using the "clip-flap method". Endoscopy 2015; 47: $262-265$

13 Takeuchi $Y$, Uedo $N$, Ishihara $R$ et al. Efficacy of an endo-knife with a water-jet function (Flushknife) for endoscopic submucosal dissection of superficial colorectal neoplasms. Am J Gastroenterol 2010; 105: $314-322$ 